\title{
Investigation of conventional deep drawing and hydroforming deep drawing via experimental and finite element simulation
}

\author{
S.A. Zahedi ${ }^{1}$, H.Goodarzian ${ }^{2}$, M.Okazi $^{2}$ and M. Bakhshi-Jooybari ${ }^{3}$ \\ ${ }^{1}$ Young Researchers club, Islamic Azad University-Jouybar branch, Iran (Zahedi 2027@gmail.com) \\ ${ }^{2}$ Islamic Azad University-Behshahr Branch, Behshahr Iran (hamed_goodarzian@yahoo.com) \\ ${ }^{2}$ Islamic Azad University-Behshahr Branch, Behshahr Iran (m.okazi@yahoo.com) \\ ${ }^{3}$ Babol Noshirvani University of Technology, Babol, Iran (Bakhshi@nit.ac.ir)
}

\begin{abstract}
Deep drawing and hydroforming deep drawing (HDD) are the two conventional methods for production of cylindrical cups. In this paper, two cylindrical workpieces have been produced with separated dies and the deformation force and sheet thickness distributions have been compared. For increasing drawing ratio in the hydroforming deep drawing, pressure chamber must be calculated and exerted properly. Limited tearing pressure curve have been obtained with finite element simulation. By considering of this approach and conducting a series of hydroforming experiments, proper pressure will be selected. Finally, workpiece was drawn with 2.3 drawing ratio by using proper pressure path. Results have shown that although hydroforming deep drawing needs more forces, more drawing ratio can be achieved as a result.
\end{abstract}

Keywords: Conventional deep drawing, Hydroforming deep drawing (HDD), Finite element simulation.

\section{Introduction}

One of the important metal forming process is "deep drawing" which has been used in a wide range of industrial applications for converting the sheet into the hallow workpiece. Recently, Conventional deep drawing has been substituted with Hydroforming deep drawing (HDD) to product industrial workpiece with high Limiting drawing ratio (LDR) (Parsa \& Darbandi, 2008). Schematic cylindrical cup drawing with HDD process is shown in Fig.1. A pressurized fluid is employed in front of the workpiece. As the punch travels, the workpiece begins to deform into a cylindrical cup (Kandil, 2003).

Some of the advantages of sheet hydroforming are improving the material formability, reduction of friction force, the accuracy of the forming part and the reduction of forming stages because of improvement in LDR (Lang et al., 2005; Oh et al., 2006).

Numerous researchers have attempted to improve drawing ratio. Yoshihara et al. (2005) have observed improvement in the LDR at $300 \circ \mathrm{C}$ by controlling a variable blank holder force (BHF) in comparison with the constant BHF conditions. For the Steel-14 sheet with the conventional deep drawing processes drawing ratio more than 2, literatures don't usually report where this drawing ratio is possible in the hydroforming deep drawing increase. One of the key parameters for increasing drawing ratio in the HDD is pressure chamber that must be calculated and exerted properly (Yossifon \& Tirosh, 1985). Wu et al. (2004) and Khandeparkar \& Liewald (2008) obtained rupture and wrinkling diagrams for stepped punches by finite element simulation and experiments. Thiruvarudchelvan and Tan (2006) performed theoretical analysis and experimental approach from hydraulic pressure-assisted deep drawing process. Hama et al. (2007) developed an elasto-plastic finite element method for the sheet hydroforming of elliptical cups. Zahedi et al. (2009) obtained tearing curve of cylindrical cup via theoretical study. They investigated on the effect of anisotropy, drawing ratio, sheet thickness and strain hardening component.

In this paper, two cylindrical workpieces have been produced with separated dies. Final workpieces have been compared in deformation force and sheet thickness distributions. In HDD limited tearing pressure curve was obtained with finite element simulation. By considering this diagram and conducting a series of hydroforming experiments, proper pressure is selected. Finally, by using proper pressure path workpiece was drawn with 2.3 drawing ratio.

\section{Finite element simulation}

The FE model is shown in Fig. 2 in an exploded view. Because of symmetry, only one-quarter of the blank and the tool components were modeled in Abaqus/CAE V6.6.

During all of simulations, tools (punch, pressure chamber components) were considered to be rigid while sheet constitute deformable material. Friction was modeled between the blank and the tool components as the Coulomb assumption. Symmetry boundary conditions were specified on the appropriate boundaries of the blank. The liquid was not modeled, but a uniform distribution pressure was applied as the fluid pressure instead directly to the blank on the die opening. For identifying the pressure area, Subroutine $\mathrm{Vd}$ load was utilized in Abaqus/CAE 6.6.

\section{Experimental work}

Two dies and experimental system are shown in Fig.3. The experiments were carried out on DMG (Denison Mayers Group) 2002 press.
Research article

CIndian Society for Education and Environment (iSee)
"Conventional deep drawing" http://www.indjst.org
Zahedi et al. Indian J.Sci.Technol. 
Fig. 1. Hydroforming Deep Drawing (HDD) process (Kandil, 2003).

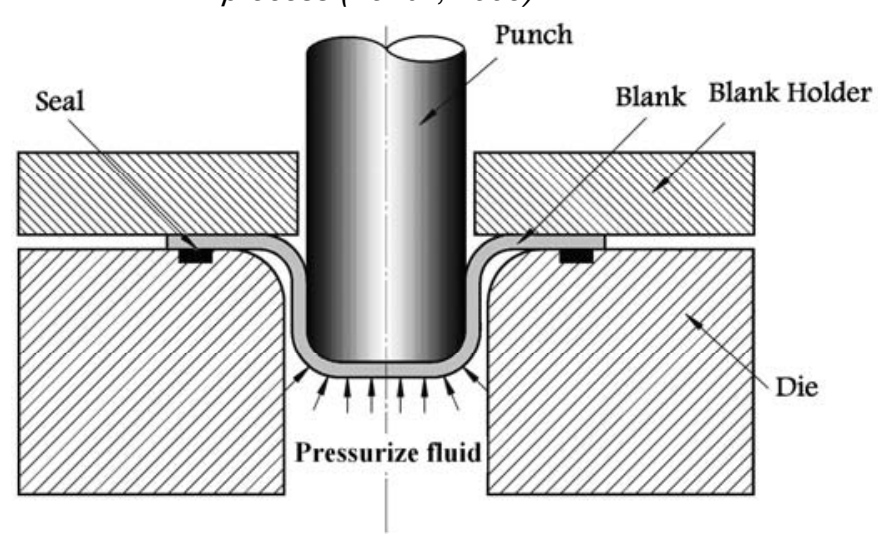

Fig. 3. Dies and experimental system . a).

Hydroforming deep drawing die component

b) Conventional Deep drawing die component; c) Die mounted on DMG press.
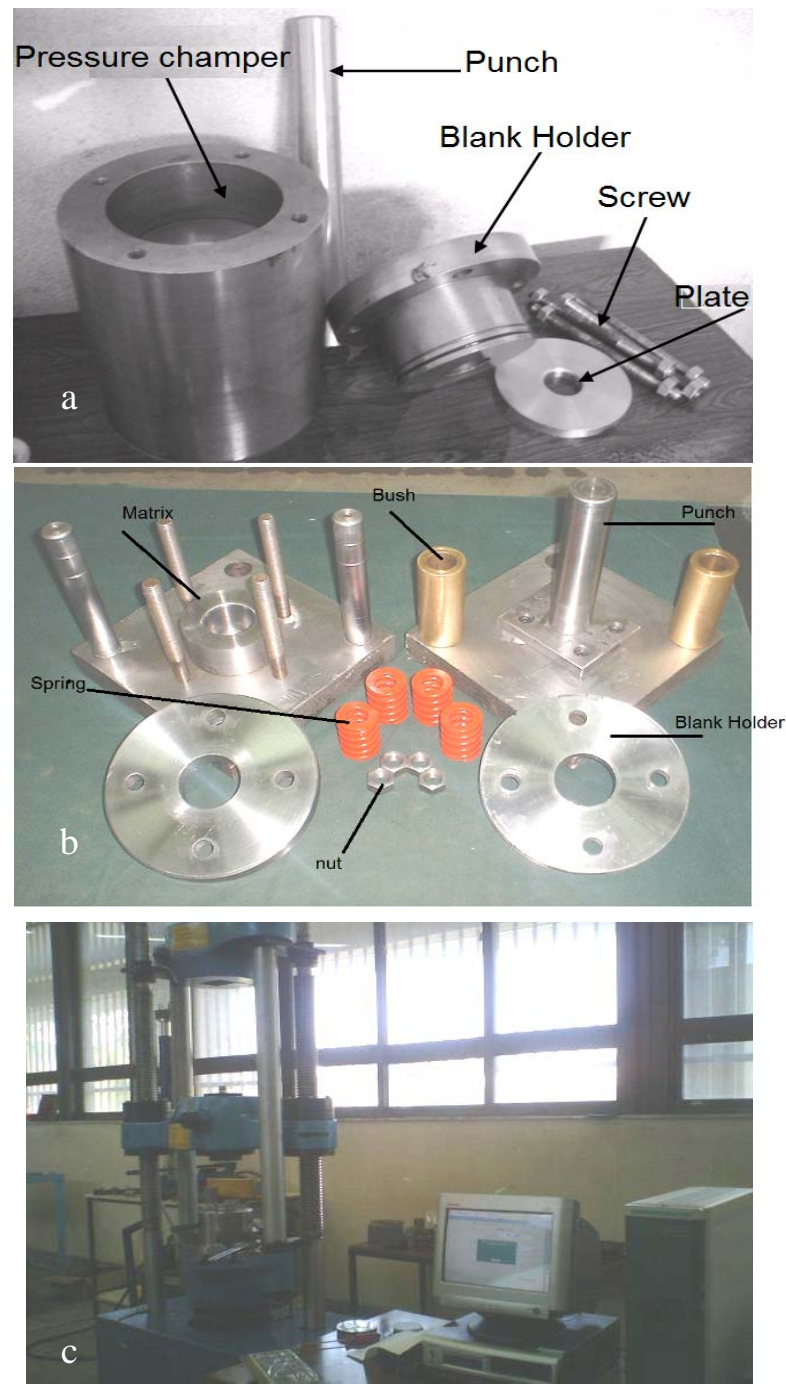

Vol. 3 No. 9 (Sep 2010)

ISSN: 0974- 6846
Fig 2. The FE model for the analysis of HDD And deep drawing in Abaqus/CAE V6.6.

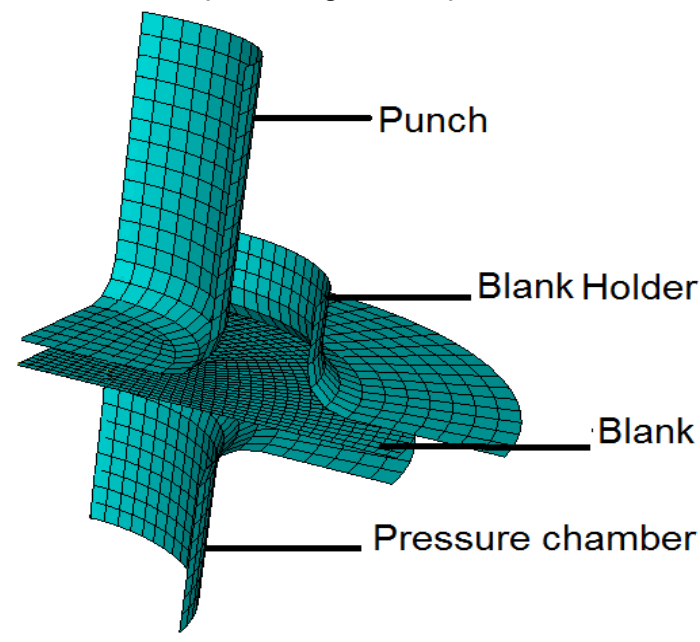

Fig. 4 Force- Stroke curves via experiment and FE simulation (St-14 sheet, $\beta=2$, sheet thickness $1 \mathrm{~mm}$ ).
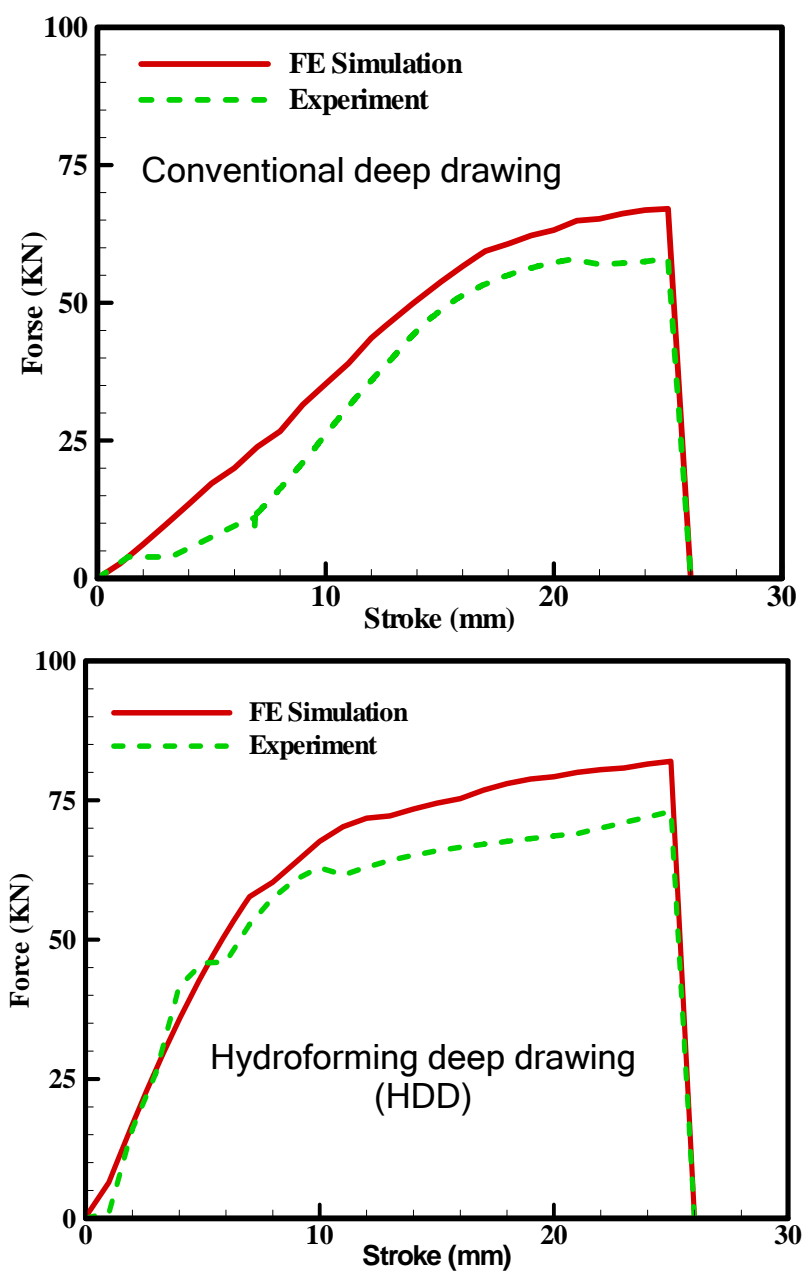
Fig. 5. Force-Stroke curve via experiment for hydroforming and deep drawing dies (St-14 sheet, $\beta=2$, sheet thickness $1 \mathrm{~mm}$ ).

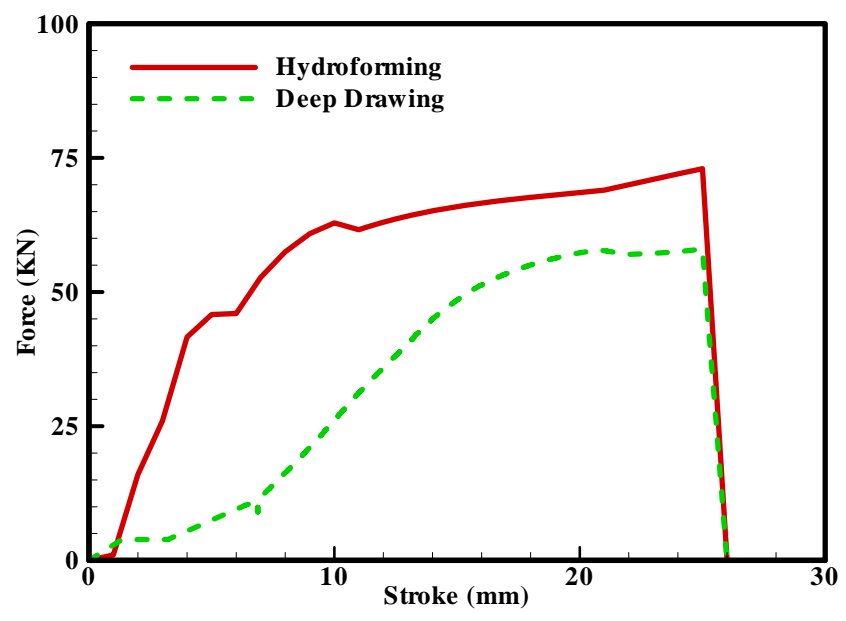

Fig. 6. Final cylindrical cup (st-14 sheet, $\beta=2$, Sheet thickness $1 \mathrm{~mm}$ ).

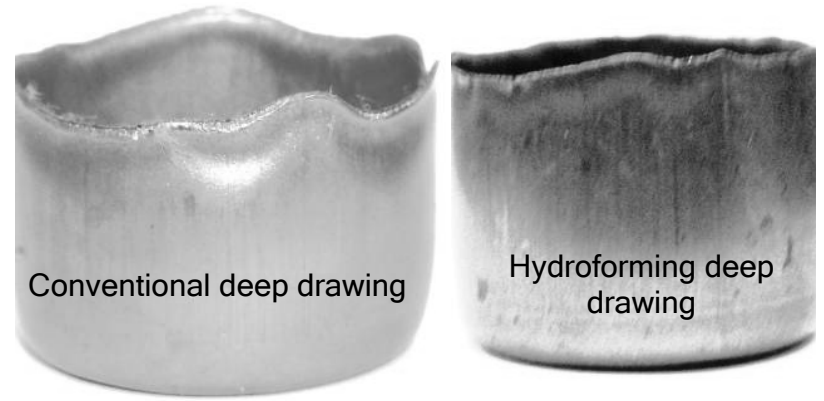

Fig. 7. Sheet thickness distribution of final workpieces, (St-14 sheet, $\beta=2$, Sheet thickness $1 \mathrm{~mm}$ )

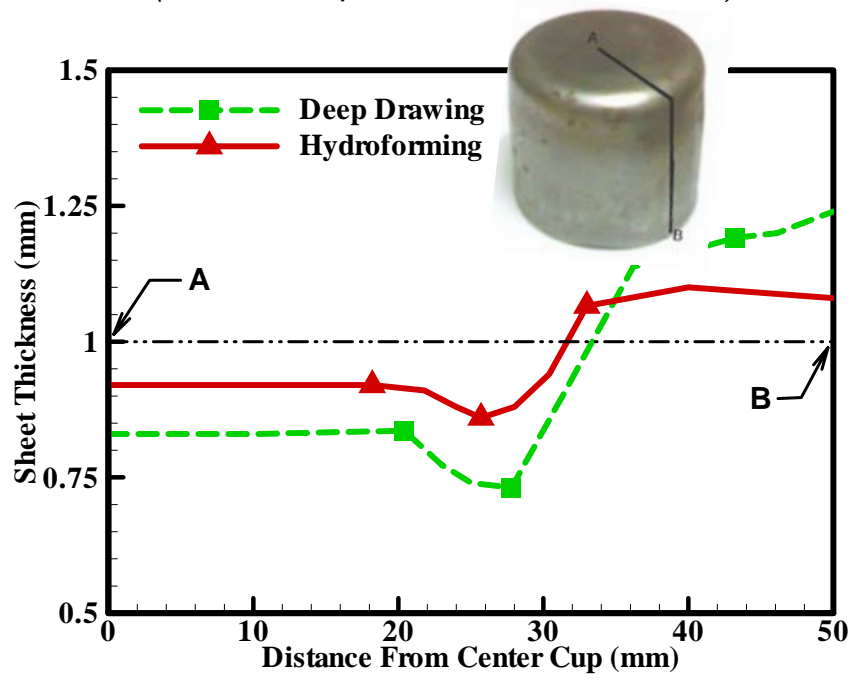

The material properties of steel 14 sheet and the process parameters are given in Table 1 \& 2 , respectively.
Vol. 3 No. 9 (Sep 2010)

ISSN: 0974- 6846

Table 1.Material properties of steel 14 sheet.

\begin{tabular}{|c|c|c|c|c|}
\hline Thickness & $\begin{array}{c}\text { Poisson } \\
\text { ratio }\end{array}$ & $\begin{array}{c}\text { Young's } \\
\text { modulus }\end{array}$ & Density & Anisotropy \\
\hline $1 \mathrm{~mm}$ & 0.3 & $\begin{array}{c}210 \\
\mathrm{GPa}\end{array}$ & $\begin{array}{c}1700 \\
\mathrm{Kg} / \mathrm{m}^{3}\end{array}$ & 1 \\
\hline
\end{tabular}

Table 2. Material processes of the experiment.

\begin{tabular}{|c|c|c|c|}
\hline $\begin{array}{c}\text { Punch } \\
\text { diameter }\end{array}$ & $\begin{array}{c}\text { Blank } \\
\text { diameter }\end{array}$ & $\begin{array}{c}\text { Friction } \\
\text { coefficient }\end{array}$ & $\begin{array}{c}\text { Blank holder } \\
\text { force }\end{array}$ \\
\hline $35 \mathrm{~mm}$ & $70 \mathrm{~mm}$ & 0.08 & $1000 \mathrm{KN}$ \\
\hline
\end{tabular}

Results and discussion

To verify the simulation result, blanks of diameters 70 $\mathrm{mm}, 1 \mathrm{~mm}$ thickness and punch head diameter $35 \mathrm{~mm}$ that has created drawing ratios $\beta=2$ were implemented. In Fig.4, the Force-Stroke curves were resulted from finite element simulation (FE) and experimental for two dies are shown. The trend of the FE simulation and experimental result show acceptable conformity.

For comparison of the force in conventional deep drawing and hydroforming, experimental date of two above curves was drawn in Fig. 5 again. It shows more forces would be consumed in hydroforming rather than deep drawing. In addition to deformation force occurred in two methods, hydroforming will have liquid resistant pressure that exert against punch travels. This phenomenon will increase the amount of force.

For comparison of the force in conventional deep drawing and hydroforming, experimental date of two above curves was drawn in Fig. 5 again. It shows more forces would be consumed in hydroforming rather than deep drawing. In addition to deformation force occurred in two methods, hydroforming will have liquid resistant pressure that exert against punch travels. This phenomenon will increase the amount of force.

The final workpieces exerted form two methods are shown in Fig.6. Sheet thickness distributions of two workpieces in A-B path are shown in Fig.7. It is necessary to say that for measurement of thickness distribution a micro ultrasonic thickness distribution was implemented. Result has shown that in hydroforming thickness distribution is more uniform than deep drawing. In fact this is the biggest advantage of hydroforming procedure which conducted cups with higher drawing ratio.

Pressure path is the most important parameter in sheet hydroforming processes. For increasing the drawing ratio, the pressure path under the sheet must exert properly. Low pressure results wrinkling of the part and excessive pressure will tear the workpiece. In order to define the tearing pressure curve, several counter pressure-punch displacement histories were prescribed for the simulation. The rupture criterion used in this paper is the critical effective strain at instability (Yossifon \& Tirosh, 1985). 
Indian Journal of Science and Technology

Fig. 8. Tearing pressure cure via FE simulation, (St-14 sheet, $\beta=2.3$, Sheet thickness $1 \mathrm{~mm}$ ).

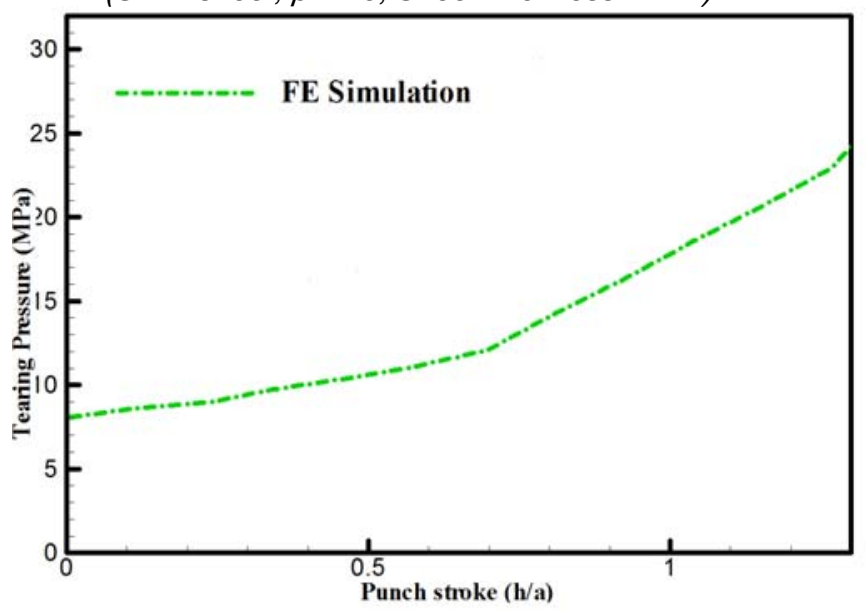

Vol. 3 No. 9 (Sep 2010)

ISSN: 0974- 6846

Fig. 9. Three pressure paths selected in tearing pressure diagram (St-14 sheet, $\beta=2.3$, Sheet thickness $1 \mathrm{~mm}$ ).

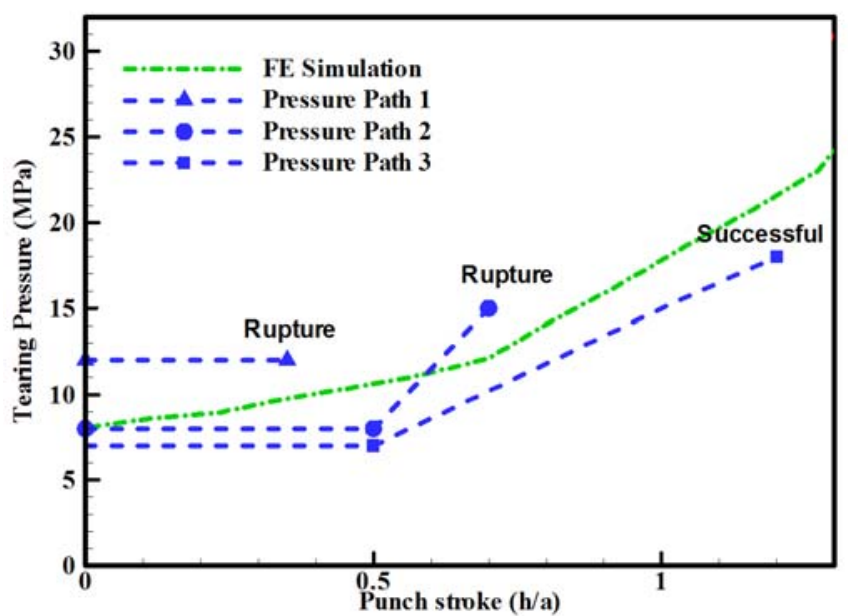

Fig. 10. Final workpieces with experimental and finite element simulation.
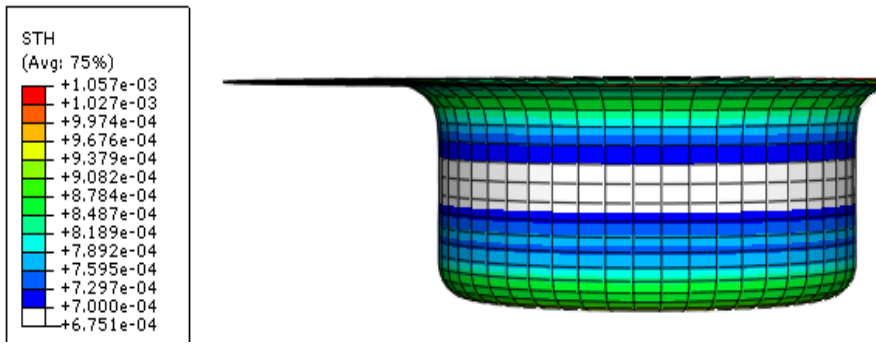

re pathuessrP 1
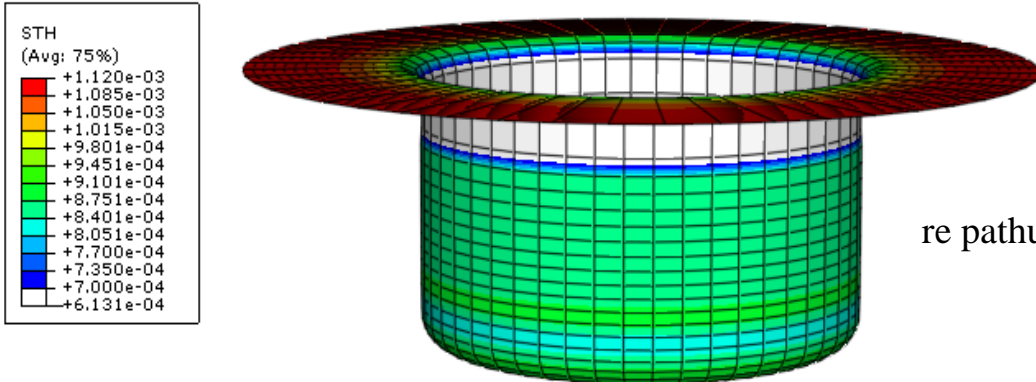

re pathuessrP 2

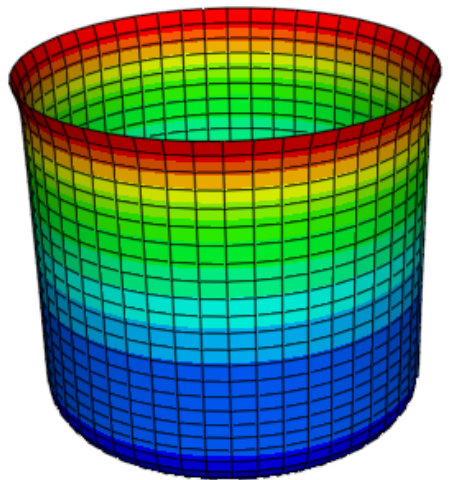

re pathuessrP 3

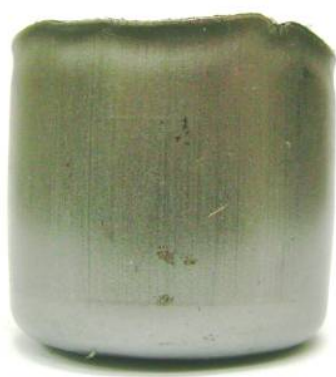




$$
\begin{aligned}
& \varepsilon_{c r}=n s \\
& S=\frac{1+R}{(1+2 R)^{\frac{1}{2}}}
\end{aligned}
$$

Fig. 8 shows the limited tearing pressure curve obtained from finite element simulation for drawing ratio 2.3. For testing tear diagram, several hydroforming experiments performed. Some pressured paths selected and tearing study on themes were investigated.

As it can be seen in Fig.9, pressure paths 1 and 2 will result rapture in the workpieces. Pressure path 1 has over pressure and as a result workpiece will tear at the first stage. Under pressure path 2, workpiece has drawn more but workpiece is finally torn. Pressure path 3 is selected near the tearing pressure path and is a proper pressure path that draws workpiece successfully. Simulation and experimental of cups under three pressure paths were illustrated in Fig. 10.

Increasing drawing ratio in cylindrical cup is shown in Fig. 11. By using proper pressure path cup was drowned with drawing ratio 2.3 .

Fig. 11 Workpieces with high drawing ratio.

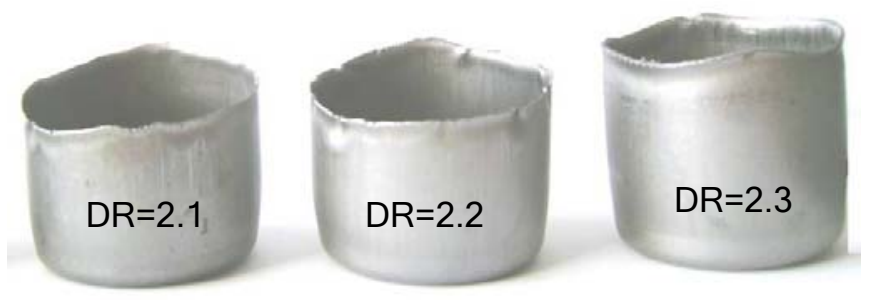

\section{Conclusion}

Hydroforming deep drawing however consumes more forces rather than conventional deep drawing; thickness distribution is more uniform, and then it will cause to produce cups with higher drawing ratio. By selecting proper pressure path, steel 14 is drawn with 2.3 drawing ratio.

\section{References}

1. Hama $T$, Hatakeyama $T$, Asakawa $M$, Amino $H$, Makinouchi A, Fujimoto $\mathrm{H}$ and Takuda H (2007) Finite-element simulation of the elliptical cup deep drawing process by sheet hydroforming. F. E in Ana. \& Des. 43, 234-246.

2. Kandil A (2003) An experimental study of hydroforming deep drawing. J. Mat. Proc. Tech. 134, 70-80.

3. Khandeparkar $T$ and Liewald M (2008) Hydromechanical deep drawing of cups with stepped geometries. J. Mat. Proc. Tech. 202, 246-254.

4. Lang L, Danckert J, Nielsen K and Zhou X (2005) Investigation into the forming of a complex cup locally constrained by a round die based on an innovative hydromechanical deep drawing method. J. Mat. Proc. Tech. 167, 191-200.

5. Oh. Soo-lk, Byung-Hee Jeon, Hyun-Yong Kim and Jae-Bong Yang (2006) Applications of hydroforming processes to automobile parts. J. Mat. Proc. Tech. $174,42-55$.

6. Parsa MH and Darbandi $\mathrm{P}(2008)$ Experimental and numerical analyses of sheet hydroforming process for production of an automobile body part . J. Mat. Proc. Tech. 198, 381-390.

7. Thiruvarudchelvan S and Tan MJ (2006) A note on fluid-pressure-assisted deep drawing processes. J. Mat. Proc. Tech. 172, 174-181.

8. Wu J, Balendra R and Qin Y (2004) A study on the forming limits of the hydromechanical deep drawing of components with stepped geometries. J. Mat. Proc. Tech. 145, 242-246.

9. Yoshihara Shoichiro, Ken-ichi Manabe and Hisashi Nishimura (2005) Effect of blank holder force control in deep-drawing process of magnesium alloy sheet. J. Mat. Proc. Tech. 170, 579-585.

10. Yossifon $\mathrm{S}$ and Tirosh $\mathrm{J}$ (1985) Rupture instability in hydroforming deep-drawing process. Int. J. Mech. Sci. 27, 559-570.

11.Zahedi SA, Shamsi Sarband A, Gorji A, Hosseinipour SJ and Bakhshi- jouybari M (2009) Theoretical study and finite element simulation of tearing in hydroforming process. Int. J. Appl. Sci. 9, 178-182. 